\title{
REFLECTION
}

\section{In, But Out of Touch: Connecting With Patients During the Virtual Visit}

\author{
${ }^{1}$ Martina Ann Kelly, MB, BCh, \\ BAO, MA, PbD, CCFP \\ ${ }^{2}$ Gerard J. Gormley, $M B, B C h, B A O$, \\ $M D$ \\ 'Department of Family Medicine, Cumming \\ School of Medicine, University of Calgary, \\ Alberta, Canada \\ ${ }^{2}$ Centre for Medical Education, Queens \\ University Belfast, Belfast, Northern \\ Ireland, UK
}

\begin{abstract}
Covid-19 has rapidly changed physician-patient interaction, from hands-on to hands-off medicine. In this essay, 2 family physicians on different continents reflect on the meaning of touch in clinical practice and how virtual care is transforming this tacit aspect of patient care. Although technology enables physicians to stay in touch with patients verbally, we have lost the ability to physically touch. Traditionally, touch is central to medical practice, physical examination guides diagnosis and informs management. But the silent language of touch fulfills a deeper symbolic function, enabling physicians to acknowledge patient concerns in a tangible way. Touch expresses healing, extending beyond skin-toskin contact to express humanity, caring, and connection. As we adapt to novel technologies, we wonder how, as family physicians, we will adapt our clinical acumen to extend our ability to connect with patients.
\end{abstract}

Ann Fam Med 2020;18:461-462. https://doi.org/10.1370/afm.2568

\section{Family Medicine Teaching Clinic, Downtown Calgary, Canada} I present a completed screening questionnaire as my temperature is checked by an unfamiliar staff member, veiled in personal protective equipment, her eyes peeping above her mask. I'm unable to see if her facial expressions are fearful or supportive. The teaming room, usually bustling with staff, residents, and extended team, is empty. I proceed to a single office, which smells of disinfectant and alcohol wipes. The morning huddle is appropriately socially distanced, staff spread out like points on a fan. I sigh, another day, virtually alone in my room, I put the phone on speaker, dial my first patient, and start my day.

Community Clinic, Belfast, Northern Ireland

The smell of coffee still percolates the air as I arrive in my family medicine clinic. However, everything is different. Instead of sitting down with my colleagues and discussing what they did at the weekend-now I dispense my coffee with a "no touch" technique and huddle at a distance. The huddle is friendly, but marked with an air of anticipation and nervousness. The waiting room, usually full of chatter, is eerily silent. I then enter my room, close the door and poise myself for remote consulting. Aside from the diligent cleaner, I have been the only person in this room in weeks. The sphygmometer lies idle, the patient's chair remains empty, otoscope fully charged and unused.

Conflicts of interest: authors report none.

\section{CORRESPONDING AUTHOR}

Martina Kelly

G329, Undergraduate Family Medicine Department of Family Medicine

Cumming School of Medicine

University of Calgary

Health Sciences Centre

3330 Hospital Drive NW

Calgary T2N 4N1, Alberta, Canada

makelly@ucalgary.ca
A $s$ if overnight, the COVID-19 pandemic has changed family medicine practice. Virtual visits, by phone or video link, are the new normal. Remote consultations allow us to stay in touch with patients; we talk, we listen, we may even see, but despite these forms of communication, we are out of touch.

No physical examination, no reaching out to reassure. Physician touch is more than skin-to-skin contact, it includes the gestures and emotions we express when we connect with our patients. Touch embodies our mandate as healers- "to cure sometimes, to treat often and to comfort always."

Historically, healing is associated with the laying on of hands, symbolizing physical care and compassion. Touch, in medicine, is most obviously 
associated with physical examination, diagnosis, and performance of procedures. Even with eyes closed, experienced physicians can feel the heat of an area of cellulitis, the dry scale of eczema, the outline of a baby's curved spine in utero as fingers grasp the hardness of its head firmly positioned in the pelvis. Perhaps even, as suggested by Polyani, ${ }_{1}$ physicians' sense of touch extends beyond the fingertips, into familiar tools such as the stethoscope, speculum, or needle, instruments become extensions of the senses. Think, for example, of the rapid rise and fall of the stethoscope on the chest of a patient with tachypnoea, or of sensing the recoil of the needle in a patient with good venous access. Alternatively, imagine the sense of discombobulation when using unfamiliar or new equipment to perform routine procedures. ${ }^{2}$ But now, doctors' diagnostic acumen relies more on verbal histories, supplemented at best, by visual supports_-video or photographs e-mailed securely, often out of focus with haphazard orientation. Medicine has been quick to prioritize visual information over less "reliable" senses such as touch and auscultation. ${ }^{3}$ The microscope and X-ray revolutionized clinical medicine, and visual insights continue to dominate our understandings of the body; for example with positron emission tomography (PET) scanning to understand organ function. Currently, there is enthusiastic adoption of ultrasound as the new "stethoscope" leading to debate about the role of bedside ultrasound as part of core curriculum for medical students. Perhaps the sound and vision of telemedicine is the new future tool of clinical care?

A more tacit aspect of touch is its role in nonverbal communication. Physicians and patients greet each other by shaking hands, fist bumps or high fives with children. Many physicians receive hugs when delivering good news - the chemotherapy is working, delivering a healthy baby! Doctors and patients reach out to each other when sharing distress or sensitive moments, a gentle touch to the patients' arm, or the fleeting touch of fingers as we pass a tissue to mop up tears. Breaking bad news over the phone was traditionally discouraged. Being with the person emphasized the importance of physician presence. Now, we extend our senses to probe the moment of silence. It feels uncomfortable to tell someone a cancer diagnosis over the phone, without the ability to touch and physically acknowledge another's suffering. Even if our eyes touch, facilitated by video, there is an emotional sense of inadequacy, words are not enough. Touch feels lacking in these disembodied impersonal virtual encounters. Touch connects doctors and patients physically and emotionally as human beings, forming a primal bond.
But at present, touch is taboo. Never entirely without risk, touch is now virally suppressed, gone. It's hands-off medicine. To touch, we gown, mask, goggle, and glove. Face-to-face communication is now more than just at arm's reach in primary care offices-now meters away across such rooms. We are in touch, but there is something missing, something evanescent. To quote the Hall \& Oates ${ }^{4}$ song, "Out of Touch:" "I'm waking up to a fantasy, the shades all around aren't the colors we used to see, we're soul alone, and soul really matters to me."

In one sense, medicine is well-prepared for this new virtual life, perhaps COVID-19 has merely hastened the inevitable; where once bureaucracy was slow and burdensome-it has now become agile and creative. Physicians have never been more connected. Video conferencing enables clinicians to congregate in cyberspace, learn online, and provide patient care. Our e-mail in-boxes and other online communication channels are bulging with updates, invitations to virtual working meetings, and even virtual dinner parties. Twitter updates, telemedicine, virtual physical examination, and robotic surgery are readily incorporated into clinical practice. There is no doubt that these advances are to the benefit of patient, physician, and trainee in this of time of hands-free medicine, but in the rush to harness such technologies we should also pause to consider any unintended consequences. Consulting with patients is not simply exchanging information. It is about a human-to-human connection embedded in trust and sincerity-especially when we find our patients at their most vulnerable. We need to safeguard our ability to reach out and touch our patients in ways we have done for centuries. With the likelihood of remote consulting continuing after COVID-19 passes, ensuring we maintain emotional connections with our patients and learn how to touch safely, from afar, is just as important as ever.

To read or post commentaries in response to this article, see it online at https://www. AnnFamMed.org/content/18/5/461.

Submitted, April 7, 2019; submitted, revised, May 14, 2019; accepted, May 19,2019.

Key words: touch; physician; COVID-19; healing; relationship-centered care; family medicine; primary care

\section{References}

1. Polanyi M. Tacit knowing: its bearing on some problems of philosophy. Rev Mod Phys. 1962;34(4):601.

2. Harris A. In a moment of mismatch: overseas doctors' adjustments in new hospital environments. Sociol Health IIIn. 2011;33(2):308-320.

3. Maslen S. Researching the senses as knowledge: a case study of learning to hear medically. Senses Soc. 2015;10(1):52-70.

4. Hall D, Oates J. Out of touch [song]. Big Bam Boom. 1984. 